\title{
Constructing Vietnamese State-Owned Corporations' Employee Motivation Model In the Era of Industry 4.0
}

\author{
PHAN MINH DUC \\ PhD. Candidate, Central Institute for Economic Management, Vietnam \\ Lecturer, Faculty of Economics, Academy of Journalism and Communication \\ No.36, Xuan Thuy str., Cau Giay distr., Hanoi, Vietnam \\ Email: phanminhduc@ajc.edu.vn; phanminhducftu@gmail.com
}

\section{DUONG NGOC ANH}

Master of Marketing Management, La Trobe University, Australia Lecturer, Faculty of Economics, Academy of Journalism and Communication

No.36, Xuan Thuy str., Cau Giay distr., Hanoi, Vietnam

Email: duongngocanh@ajc.edu.vn; duongngocanh32@gmail.com

\begin{abstract}
Industry 4.0 has set a harshly competitive context for world of business. In that context, Vietnam economy has been preparing for the giant battle ahead; and the crucial part of that preparation process lies in the leading state-owned enterprises of Vietnam. This is mainly because they have received many privileges from the government to become the driver of the national economy. Thus, there is an urge for 10 biggest state-owned corporations (SOCs) among those to do somethings to prepare for the upcoming changes in human life, work and demands, especially things with their human resources management. This paper has a focus on employee motivating issues in the SOCs because this a crucial task to raise the labourers' productivity and enliven their working spirit. Therefore, the research has been conducted through an intensive survey with various labourers in these 10 SOCs. Their responses have been arranged into 5 different groups of contents due to the stages of A. Maslow hierarchy of needs (1943), which the research bases on as an initial researching framework. SPSS version 22 has been used to help the researchers analyse the data which have been collected from the survey. The final aim is to visualise a new concept of motivational model for the SOCs' employees in the context of Vietnam. The model, then, is inferred from the regression equation of employee motivation status (EMS) and other nine affecting factors. Hopefully, this can suggest some adaptive actions to the management of the SOCs.
\end{abstract}

Keywords: Employee Motivation, Human Resources Management, Industry 4.0, State-Owned Enterprise, Vietnam.

\section{Introduction}

Industry 4.0 has set a herald of a next revolution in the world of business since the day the term was coined in 2011 in Germany (Jozef Hercko, Jozef Hnat, 2015). Fundamentally, it is thought to be built on the foundation of the Industry 3.0, which was widely known to have gone with the automation in manufacturing industries. The Industry 4.0 is believed to combine the human beings' accomplishments in a variety of fields in a highly digitalised context, making the lines between the industries to be blurred and 
connecting the physical, digital and biological worlds into one common habitat (Klaus Schwab, 2016). In this, the world manufacturing forces have to be adapted to the changes in ways people produce things, provide the services and live in an unprecedented direction in their empirical knowledge. Those changes have been characterised through nine areas of innovation, such as big data analysis, autonomous robotics, reality simulation, system integration, IoT, cybersecurity, cloud computing, additive manufacturing and augmented reality (Markus Lorenz et al., 2015). They pose the threats to the job opportunities of the working classes, businesses of the enterprises and even the country governance of the authorities in the whole world, especially the small and developing ones with less resistant ability and more vunerable possibility to the rapid impulses that are happening.

In that context, Vietnam, a small but important country in terms of geoeconomics and geopolitics in the ASEAN region, has been being very determined to pursue its ideology of a communist society with a crucial role of the state-owned enterprises (SOEs) in leading the national economy (VOV, 2017). Moreover, the SOEs are led by the 10 biggest mother-daughter modelled corporations (litterally called $S O C S$ ) in either heavy and light industries or service sector, including chemistry (Vinachem), oil and petrol (Petrolimex, PVN), coal and mining (Vinacomin), electricity (EVN), rubber (VRG), telecommunication and information technology (VNPT, Viettel), textile (Vinatex) and finance-banking (Bao Viet) (Nguyen Thanh Hai, 2016). In table.1, the annual revenue/GDP ratios of the SOCs in the period of 2014-2016 have been accounted for $24 \%-28 \%$. This proves their driving power to the national economy.

Table 1. Vietnam SOCs' revenue/GDP ratios, 2014-2016 Unit: US\$

\begin{tabular}{|l|c|c|c|c|}
\hline \multicolumn{2}{|c|}{ Corporations } & $\mathbf{2 0 1 4}$ & $\mathbf{2 0 1 5}$ & $\mathbf{2 0 1 6}$ \\
\cline { 3 - 5 } & Revenue* & Revenue* & Revenue* $^{*}$ \\
\hline 1 & Bao Viet & $611,519,015$ & $712,508,244$ & $873,950,319$ \\
\hline 2 & EVN & $8,909,606,507$ & $10,275,225,324$ & $12,223,829,413$ \\
\hline 3 & Petrolimex & $9,092,679,710$ & $6,444,449,330$ & $5,413,365,575$ \\
\hline 4 & PVN & $16,414,376,786$ & $12,901,296,988$ & $10,287,975,379$ \\
\hline 5 & Viettel & $8,661,244,230$ & $9,791,162,893$ & $9,960,782,590$ \\
\hline 6 & Vinachem & $1,812,134,535$ & $1,810,727,632$ & $1,768,608,485$ \\
\hline 7 & Vinacomin & $3,433,941,526$ & $3,359,375,687$ & $4,448,450,209$ \\
\hline 8 & Vinatex & $593,009,453$ & $667,443,394$ & $680,852,935$ \\
\hline 9 & VNPT & $2,248,889,866$ & $2,224,049,242$ & $2,336,293,691$ \\
\hline 10 & VRG & $758,496,373$ & $664,585,623$ & $691,316,773$ \\
\hline \multicolumn{2}{|c|}{ Vietnam GDP** } & $52,535,898,000$ & $48,850,824,357$ & $48,685,425,368$ \\
\hline \multicolumn{2}{|c|}{ Ratio (\%) } & $\mathbf{1 8 6 , 2 0 5 , 0 0 0 , 0 0 0}$ & $\mathbf{1 9 3 , 2 4 1 , 0 0 0 , 0 0 0}$ & $\mathbf{2 0 2 , 6 1 6 , 0 0 0 , 0 0 0}$ \\
\hline
\end{tabular}

*.Compiled from the corporations' annual reports. Current exchange rate of Joint Stock Commercial Bank for Foreign Trade of Vietnam (VCB): 22,745VND = 1 USD

** World Bank Data for Vietnam (https://data.worldbank.org), date of access: $22^{\text {nd }}$ Nov.2017 Source: Authors' research (2017)

Moreover, SOCs are considered the pillar and the main driver of the economic system of the country because of their being granted priorities in capital, land and human resources usage. Thus, in the economic integration process of Vietnam, the 10 corporations have to cope with the urge of adjusting their business models and preparing their human capital for the requirements of the new job specifications in the fourth industrial revolution (Konstantin M. Wacker, 2016). This, on one hand, may involve employee retainment to deploy the up-to-date business strategies. On the other hand, this certainly requires a feasible strategy of employee motivation for them to be loyal, common target-oriented, innovative and enthusiastic in work to produce better results for the corporations' higher competency in their global businesses.

Regarding employee motivation, there have been many researches and models that instruct the managers of the companies how to stimulate their subordinates' interests at work. The prominent ones are Abraham 
Maslow's hierarchy of needs (1943), which classifies people ascending needs into five stages of a pyramid (psychological, safety, belongingness and love, self-esteem and self-actualisation) (Mahmoud A.Wahba, Lawrence G.Bridwell, 1976); Frederick Herzberg's two-factor theory (1959), which divides employee motivating factors into two groups of creating job satisfaction and dissatisfaction (George K.A., 2011); David McClelland's three needs theory (1961), which explains how the achievement, power and affiliation monitor the acts of workers from a managerial perspective (Zulkiflee D., Shahrom T., 2013); Victor Vroom's expectancy theory (1964), which reveals the relationship between expectancy, instrumentality and valence in contributing to the trigger of human behavior (Pranav Parijat, Shilpi Bagga, 2014); Richard Hackman and Greg Oldham's job characteristics theory (1980), which proposes a model of work features of five that influence the employees' final outcomes (Richard Hackman, Greg. R. Oldham, 1976). Among these, the classic model of A.Maslow has become the most cited theory in the field of motivation. This is partly because it is easy to be comprehended and used. The hierarchy mentions people needs from the very first stage of psychological needs, such as food, water, warmth and sex, the second stage of security and safety, then the belonging and love needs with the intimacy that people create towards their friends and organisations, to self-esteem (personal prestige and accomplishments) and self-actualisation (one's full potentials fulfilling) stages at the peak (A.Maslow, 1943). Normally, people have to act to meet these needs from the bottom to the peak of the hierarchy again and again. This also resembles the daily tasks of a typical employee in Vietnamese enterprises. Therefore, the authors have decided to use it as the guidance on contents of employee motivation that the ongoing model should embrace.

\section{Methodology}

This paper uses the A.Maslow's hierrarchy of needs as the research framework for the survey, which has been designed in 34 questions including 4 demographic ones and the rest 30 for testing the different needs status of the corporations' 896 employees (in Likert scale of 5), mainly focused on the direct labourers working at sites and in the offices. The respondents are asked to rate their motivational state from the most negative level of $0 / 1$ to the most positive level of $4 / 5$. All of the questions have been coded for convenient data collection and analysis (see tab.2).

During the surveying period of 2016 - 2017, the snowball sampling method (Mark Saunders et. al., 2012) has been used to enable the authors to get as many valid and relevant response as possible for more precise conclusions in the SPSS 22.0 regression analysis. This non-probability sample can also help the authors overcome their lack of close relationship with the respondents. The analysis, in turn, first comes along with the Cronbach's Alpha calculation to identify irrelevant questions to be crossed off. Then, the exploratory factor analysis (EFA) is utilised with the use of KMO and Bartlett's tests and the rotated component matrix from the Principal Component Analysis (PCA) in combination with Varimax rotation method (Hair, J.F. Jr., Anderson, R.E., Tatham, R.L., \& Black, W.C., 1998). Lastly, it ends with the regression model on the employee motivation for the SOCs in Vietnam, which will be used for the formation of the new motivational model that is to be proposed to the corporations and managing authorities.

Table 2. Encoding the questions in the survey for SPSS analysis

\begin{tabular}{|c|c|c|}
\hline Variables & Codes & Question contents \\
\hline \multirow{8}{*}{ 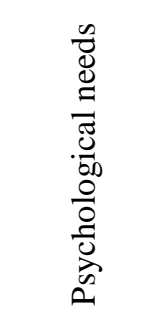 } & PS11 & Monthly income \\
\hline & PS12 & Annual bonus package \\
\hline & PS13 & Annual total income \\
\hline & PS21 & Hygienic conditions of the working place \\
\hline & PS22 & Working environment \\
\hline & PS23 & Creative arrangement of the working place \\
\hline & PS31 & Modern working equipments \\
\hline & PS32 & Resting places and cafeteria \\
\hline
\end{tabular}




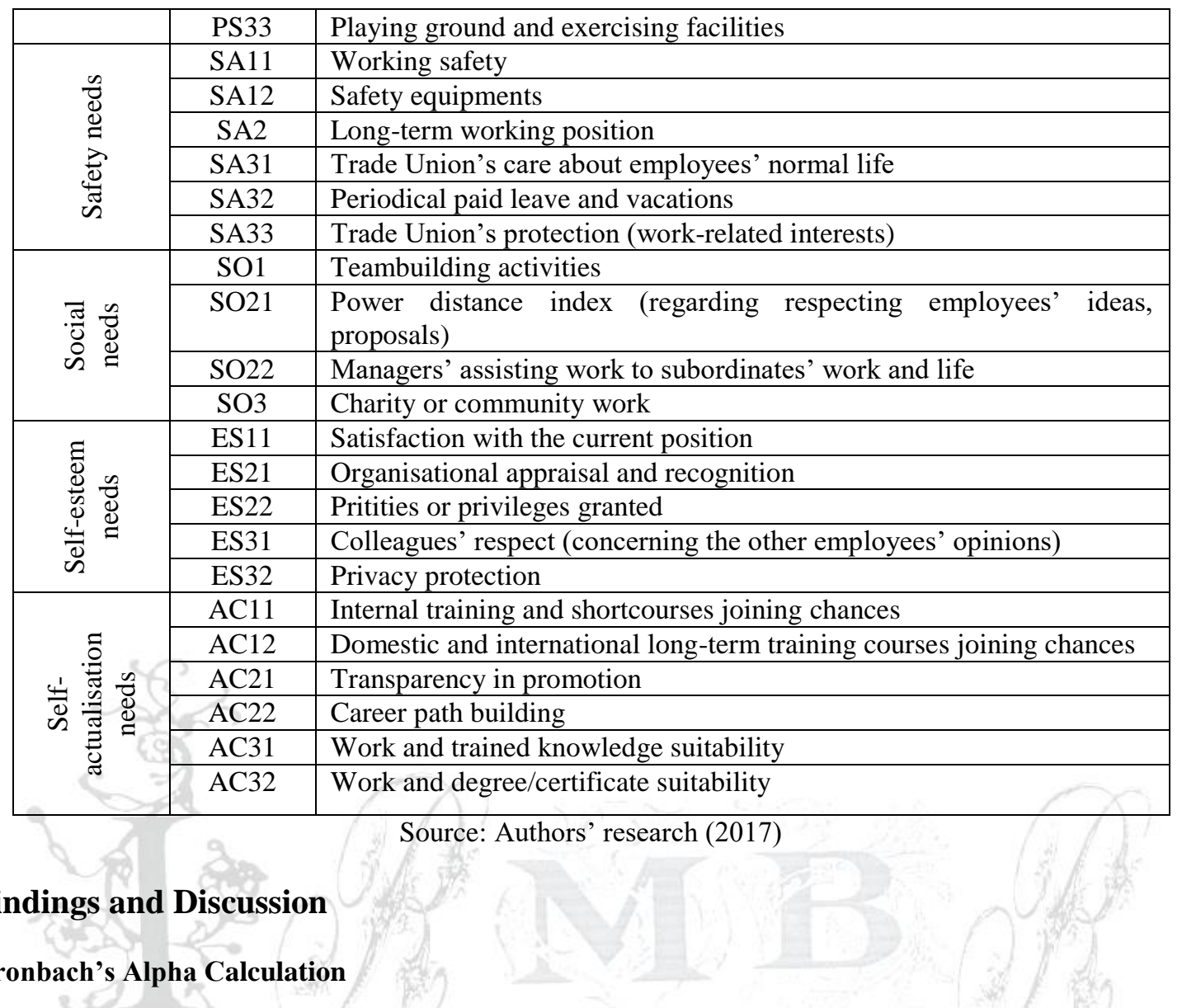

The variables with Cronbach's $\alpha$ of below 0.7 and the corrected item-total correlation coefficient of below 0.3 are not acceptable and the questions are deemed unreliable to the research results (Nunnally, J. C., Bernstein, I.H., 1994). Therefore, removing 9 questions that are not fitted with the aforementioned conditions, the authors keep the following 21 variables for further analyses.

- $\quad$ PS group (6): $\alpha=0.804$ (PS11, PS13, PS22, PS23, PS31 and PS33)

- $\quad$ SA group (4): $\alpha=0.799$ (SA11, SA12, SA32 and SA33)

- $\quad$ SO group (3): $\alpha=0.802$ (SO1, SO21 and SO3)

- $\quad$ ES group (5): $\alpha=0.822$ (ES1, ES21, ES22, ES31 and ES32)

- $\quad \operatorname{AC}$ group (3): $\alpha=0.834$ (AC11, AC12 and AC22)

\section{Exploratory factor analysis (EFA)}

The EFA is used with the PCA and the Varimax rotation method at the (Eigenvalues) $\lambda \geq 1$. This method requires that the following conditions are met for the reliable rotated component matrix afterwards (Lawrence S. Meyers et. al., 2013).

- Cummulative extraction sums of squared loadings $\geq 50 \%$,

- $\quad 01 \geq \mathrm{KMO} \geq 0.5$, and

- $\quad$ (Bartlett's test of sphericity) Sig. $<0.05$ 
Table 3. KMO and Bartlett's tests with variables

\begin{tabular}{|c|c|c|c|c|c|c|c|c|c|}
\hline \multicolumn{7}{|c|}{ Kaiser-Meyer-Olkin Measure of Sampling Adequacy. } & \multicolumn{3}{|l|}{0.876} \\
\hline \multirow{3}{*}{\multicolumn{4}{|c|}{ Bartlett's Test of Sphericity }} & \multicolumn{3}{|c|}{ Approx. Chi-Square } & \multicolumn{3}{|c|}{18679.799} \\
\hline & & & & \multicolumn{3}{|c|}{$\mathrm{df}$} & \multicolumn{3}{|c|}{210} \\
\hline & & & & \multicolumn{3}{|c|}{ Sig. } & \multicolumn{3}{|c|}{0.000} \\
\hline \multirow[b]{2}{*}{ Factor } & \multicolumn{3}{|c|}{ Initial Eigenvalues } & \multicolumn{3}{|c|}{$\begin{array}{l}\text { Extraction sums of squared } \\
\text { loadings }\end{array}$} & \multicolumn{3}{|c|}{$\begin{array}{c}\text { Rotation sums of squared } \\
\text { loadings } \\
\end{array}$} \\
\hline & Total & $\begin{array}{c}\% \text { of } \\
\text { variance }\end{array}$ & $\begin{array}{l}\text { Cummu } \\
\text { lative } \%\end{array}$ & Total & $\begin{array}{c}\% \text { of } \\
\text { variance }\end{array}$ & $\begin{array}{l}\text { Cummu } \\
\text { lative } \%\end{array}$ & Total & $\begin{array}{c}\% \text { of } \\
\text { variance }\end{array}$ & $\begin{array}{l}\text { Cummul } \\
\text { ative } \%\end{array}$ \\
\hline 1 & 10.693 & 50.920 & 50.920 & 10.693 & 50.920 & 50.920 & 5.159 & 24.568 & 24.568 \\
\hline 2 & 2.249 & 10.711 & 61.631 & 2.249 & 10.711 & 61.631 & 4.636 & 22.078 & 46.646 \\
\hline 3 & 1.685 & 8.026 & 69.657 & 1.685 & 8.026 & 69.657 & 4.197 & 19.986 & 66.632 \\
\hline 4 & 1.161 & 5.530 & 75.187 & 1.161 & 5.530 & 75.187 & 1.797 & 8.555 & 75.187 \\
\hline 5 & 0.893 & 4.254 & 79.441 & & & & & & \\
\hline 6 & 0.747 & 3.559 & 83.000 & & & & & & \\
\hline 7 & 0.590 & 2.811 & 85.811 & & & & & & \\
\hline 8 & 0.470 & 2.239 & 88.049 & & & & & & \\
\hline 9 & 0.366 & 1.741 & 89.791 & & & & & & \\
\hline 10 & 0.326 & 1.554 & 91.345 & & & & & & \\
\hline 11 & 0.288 & 1.373 & 92.718 & & & & & & \\
\hline 12 & 0.280 & 1.332 & 94.050 & & & & & & \\
\hline 13 & 0.212 & 1.009 & 95.059 & & & & & & \\
\hline 14 & 0.197 & 0.937 & 95.995 & & & & & & \\
\hline 15 & 0.180 & 0.857 & 96.853 & & & & & & \\
\hline 16 & 0.177 & 0.845 & 97.697 & & & & & & \\
\hline 17 & 0.145 & 0.693 & 98.390 & & & & & & \\
\hline 18 & 0.116 & 0.553 & 98.943 & & & & & & \\
\hline 19 & 0.096 & 0.456 & 99.398 & & & & & & \\
\hline 20 & 0.067 & 0.320 & 99.719 & & & & & & \\
\hline 21 & 0.059 & 0.281 & 100.000 & & & & & & \\
\hline
\end{tabular}

Source: Authors' research (2017)

The table. 3 shows that $(\mathrm{KMO}=0.876)>0.5$, Bartlett's test Sig. $=0.000<0.05$, then the variables are correlated in general. Moreover, the cummulative extraction sum of squared loadings is of $75.187 \%$ $(>50 \%)$. This illustrates that the 4 extraction factors can explain $75.187 \%$ of the data fluctuation at the Eigenvalues of $1.161(>1)$. Later on, we have a concise rotated component matrix as the results of iterations and rotation to leave out some factors, for they are not fitted with the conditions (Maximum |Factor Loading| of each variable $\geq 0.4$, and in each factor the discrepancy between the maximum |Factor Loading| and any other |Factor Loading| should be 0.3 or above) (Lawrence S. Meyers et. al., 2013) (see table.4). 
Table 4. Final rotated component matrix ${ }^{\mathrm{a}}$

\begin{tabular}{|l|c|c|}
\hline \multirow{2}{*}{} & 1 & 2 \\
\cline { 2 - 3 } & 0.847 & \\
\hline PS31 & 0.801 & \\
\hline PS23 & 0.770 & \\
\hline SO21 & 0.746 & 0.859 \\
\hline PS33 & 0.533 & 0.828 \\
\hline ES32 & & 0.783 \\
\hline SE32 & & 0.778 \\
\hline SE33 & & \\
\hline ES31 & & \\
\hline Extraction method: Principal Component Analysis. \\
Rotation method: Varimax with Kaiser Normalization. \\
\hline a. Rotation converged in 03 iterations. \\
\hline
\end{tabular}

Source: Authors' research (2017)

\section{Regression analysis}

Table 4 leads us to the idea of forming a multivariate linear equation between employee's motivation status (coded as EMS, calculated by the mean of all of variables) and the nine variables left above. The general equation shall look like:

\section{$\mathrm{EMS}=\beta_{0}+\beta_{1} \cdot \mathrm{PS} 31+\beta_{2} \cdot \mathrm{SE} 12+\beta_{3} \cdot \mathrm{PS} 23+\beta_{4} \cdot \mathrm{SO} 21+\beta_{5} \cdot \mathrm{PS} 33+\beta_{6} \cdot \mathrm{ES} 32+\beta_{7} \cdot \mathrm{SE} 32+\beta_{8} \cdot \mathrm{SE} 33+\beta_{9} \cdot \mathrm{ES} 31+\varepsilon_{\mathrm{i}}$}

In which, EMS is a dependent variable; other 9 variables are independent ones; $\varepsilon_{\mathrm{i}}$ is the residual error (unmeasured item), while $\beta_{0}$ is the EMS-intercept and $\beta_{1}, \beta_{2}, \beta_{3}, \beta_{4}, \beta_{5}, \beta_{6}, \beta_{7}, \beta_{8}, \beta_{9}$ are the regression coefficients that we need to find out in the following regression analysis. However, we still need to check the correlations between the 9 variables and EMS by taking the Pearson test beforehand. Because of the limitation of the research presenting space, the authors would like to merely inform that the test has been well done with Sig. $(<0.05)$ and/or $(<0.01)$ and all of the Pearson correlations coefficients are of $(1 ; 1)$, which meet the statistical requirements for the research to continue to the final phase of the analysis.

Table 5. Multivariate linear regression results for SOCs' employee motivation

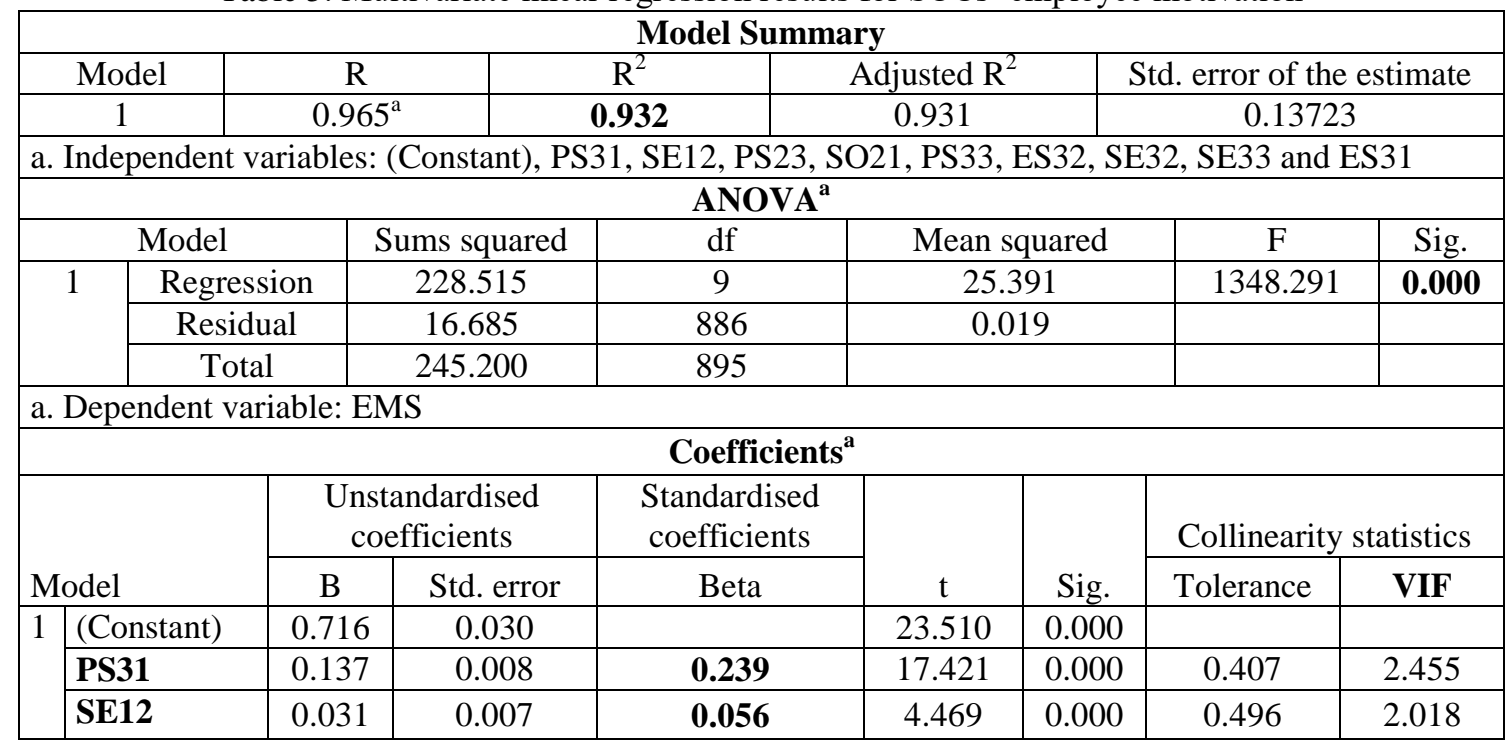




\begin{tabular}{|l|l|l|l|l|l|l|l|}
\hline PS23 & 0.092 & 0.005 & $\mathbf{0 . 2 3 0}$ & 18.819 & 0.000 & 0.516 & 1.938 \\
\hline SO21 & -0.016 & 0.008 & $\mathbf{- 0 . 0 2 5}$ & -2.061 & 0.040 & 0.521 & 1.918 \\
\hline PS33 & 0.100 & 0.006 & $\mathbf{0 . 1 8 0}$ & 17.555 & 0.000 & 0.732 & 1.366 \\
\hline ES32 & 0.118 & 0.009 & $\mathbf{0 . 2 0 8}$ & 12.471 & 0.000 & 0.277 & 3.607 \\
\hline SE32 & 0.080 & 0.009 & $\mathbf{0 . 1 4 0}$ & 9.076 & 0.000 & 0.324 & 3.087 \\
\hline SE33 & 0.116 & 0.008 & $\mathbf{0 . 1 8 5}$ & 13.614 & 0.000 & 0.415 & 2.408 \\
\hline ES31 & 0.111 & 0.007 & $\mathbf{0 . 1 7 7}$ & 14.785 & 0.000 & 0.538 & 1.860 \\
\hline
\end{tabular}

Source: Authors' research (2017)

As in table.5, $\mathrm{R}^{2}=0.932$, so the independent variables can help explain $93,2 \%$ the fluctuation of value of the dependent variable of EMS. This is a very good level of $\mathrm{R}^{2}$ to show that the following regression equation is reliable. Moreover, Sig. $=0.000(<0.05)$, then we can reject the null hypothesis $\left(\mathrm{H}_{0}:: \beta_{1}=\beta_{2}=\right.$ $\beta_{3}=\beta_{4}=\beta_{5}=\beta_{6}=\beta_{7}=\beta_{8}=\beta_{9}=0$ ) to prove that there exist a linear relationship between the independent variables and EMS. And, all of the VIF are below 10 that assures us of the non-existence of the multicollinearity. Therefore, the equation is formed as below:

$\mathbf{E M S}=0,239 * \mathbf{P S 3 1}+0,056 * \mathbf{S A 1 2}+0,230 * \mathbf{P S 2 3}-0,025 * \mathbf{S O 2 1}+0,18 * \mathbf{P S 3 3}+0,208 * \mathbf{E S 3 2}+$ $0,14 * \mathbf{S A 3 2}+0,185 * \mathbf{S A 3 3}+0,177 * \mathbf{E S 3 1}$

From this regression equation, an idea of new model of employee motivation can be proposed primitively as in Fig.1.

PS23: Creative arrangement of the working place

PS31: Modern working equipments

ES32: Privacy protection

\begin{tabular}{|c|}
\hline Highly influential factors \\
$\downarrow$
\end{tabular}

\begin{tabular}{|l|} 
EMPLOYEE MOTIVATION \\
\hline Moderately influential factors \\
\hline SA33: Trade Union's protection at work \\
\hline ES33: Playing ground and exercising facilities \\
\hline SA32: Periodical paid leave and vacations \\
\hline
\end{tabular}

Figure 1. Proposed model of employee motivation for Vietnam SOCs

*. having a reverse relationship with motivation

Source: Authors' research (2017) 


\section{Conclusion}

As can be seen in the Fig.6, the determinants of the Vietnamese SOCs' employee motivation should be divided into 3 groups: highly influential factors (with weight of 0.2 and above), moderately influential factors (with weight of 0.1-0.2) and less influential factors (with weight of less than 0.1) to show the level of importance of the corresponding work that the SOCs' management need to take to stimulate their employees working spirit. Noteworthily, the proposed model has not mentioned any of the selfactualisation motivational scheme that the management should deploy, partly because this range of factors is not really important to the SOCs' labourers at large. The major focus in the motivating scheme of their should be spent on the first two stages of Maslow's hierarchy of needs (PS23, PS31, SA33, PS33, SA32 and SA12). However, the management here also should bear in mind that the higher the PDI is the lower the motivational state that the employees may have to pursue establishing an open working environment with collaboration and harmony between them and their subordinates.

\section{References}

A.Maslow. (1943). A theory of human motivation. Psychological Review, 50, 370-396.

George K.A. (2011). Application of Frederick Herzberg's Two-Factor theory in assessing and understanding employee motivation at work: a Ghanaian Perspective . European Journal of Business and Management, 3(9), 1-8.

Hair, J.F. Jr., Anderson, R.E., Tatham, R.L., \& Black, W.C. (1998). Multivariate Data Analysis (5th ed.). Upper Saddle River, NJ.: Prentice Hall.

Jozef Hercko, Jozef Hnat. (2015, June). Industry 4.0 - a new era of manufacturing. Retrieved 11 22, 2017, from https://www.researchgate.net/publication/285597327

Klaus Schwab. (2016). World Economic Forum: The Fourth Industrial Revolution: what it means, how to respond. Retrieved 11 22, 2017, from https://www.weforum.org/agenda/2016/01/the-fourth-industrialrevolution-what-it-means-and-how-to-respond/

Konstantin M. Wacker. (2016, 8 23). Restructuring of the SOE Sector in Vietnam: Where Do We Stand and What are the Challenges Ahead? Retrieved 11 22, 2017, from https://dx.doi.org/10.2139/ssrn.2828197

Lawrence S. Meyers et. al. (2013). Performing Data Analysis Using IBM SPSS (1st ed.). New York : Wiley Publishing.

Mahmoud A.Wahba, Lawrence G.Bridwell. (1976). Maslow Reconsidered: A review of research on the Need Hierarchy Theory. Organizational behavior and human performance, 15(2), $212-240$.

Mark Saunders et. al. (2012). Research Methods for Business Students (6th ed.). Essex, England: Pearson Publishing.

Markus Lorenz et al. (2015). Industry 4.0: The Future of Productivity and Growth in Manufacturing Industries. Boston: The Boston Consulting Group, pp.4-7.

Nguyen Thanh Hai. (2016). Strategic Management in Vietnam State-Owned Enterprises (SOE). International Journal of Business and Management, 11(2), 197-204.

Nunnally, J. C., Bernstein, I.H. (1994). Psychometric Theory (3rd ed.). New York: McGraw-Hill.

Pranav Parijat, Shilpi Bagga. (2014). Victor Vroom's Expectancy Theory of Motivation - An Evaluation . International Research Journal of Business and Management, 7(9), 1-8.

Richard Hackman, Greg. R. Oldham. (1976). Motivation through the design of work: Test of a theory. Organizational Behavior and Human Performance, 16, 250 - 279.

Vov. (2017). Party Central Committee issues three resolutions on economic issues. Retrieved 11 22, 2017, from http://english.vov.vn/domestic/party-central-committee-issues-three-resolutions-on-economicissues-351100.vov

Zulkiflee D., Shahrom T. (2013). The Relationship between Employees' Need and the Formation of Trade Union: The Malaysian Manufacturing Company's Experience. International Journal of Business and Social Science, 4(13), 125-134. 